\title{
Determinants of the construction investment project management perfor- mance: Evidence at Vietnam small and medium sized enterprises
}

\author{
Vu Ngoc Xuan ${ }^{a^{*}}$ \\ C H R O N I C L E

\begin{tabular}{l}
\hline Article history: \\
Received: April 82020 \\
Received in revised format: May \\
42020 \\
Accepted: May 222020 \\
Available online: \\
May 22 2020 \\
\hline Keywords: \\
Enterprise (Es) \\
Small and Medium sized Enter- \\
prise (SMES) \\
Project Management (PM)
\end{tabular}

${ }^{a}$ Centre for Forecasting and Sustainable Development, National Economics University Hanoi, Vietnam

\section{Introduction}

Managing effective construction investment projects is one of the leading factors to evaluate a successful construction investment project (Toffolo et al., 2016). Effective management of construction investment projects is a complex process, including planning, monitoring and control of all aspects of a construction investment project; stimulate all participants in the construction investment project to achieve the objectives of the construction investment project on time with the existing costs, quality and capabilities (Villafáñez et al., 2018). However, the construction industry is one of the specific industries, so there are many difficulties during the construction process, such as problems with administrative procedures, contractor capacity (construction party), private investors, advice and some requirements during the construction process from the investor (Villafáñez \& Poza, 2010). Besides, the construction industry is also affected by many objective and subjective factors such as environment, weather, labor, equipment, materials (Zheng et al., 2014). The slow progress of construction investment project in the provinces and cities in Vietnam today has caused a number of negative effects on individuals and society (Zuluaga et al., 2007). This also leads to wasting human resources, material resources, reducing the efficiency of capital use, not achieving the goal of creating favorable

* Corresponding author.

E-mail address: xuanvn@neu.edu.vn (V.N. Xuan)

(C) 2020 by the authors; licensee Growing Science, Canada doi: $10.5267 / \mathrm{j} . j p m .2020 .5 .002$

\begin{abstract}
The objective of this study is to identify factors affecting the performance of the construction investment project management in Vietnam. The author conducted a survey at 458 small and oftware for analysis, some analytical methods were used such as: descriptive statistical methAnalysis (EFA) method. We calculated the average value of the scale to assess the influence of independent factors on the dependent variable. Multivariate regression analysis method was also used to test the suitability of the research model. The research results indicate that the effectivefactors including (1) Consultants; (2) Investor; (3) Contractors; (4) Capital sources; (5) External factors and (6) Advantages in the implementation process of construction investment projects. factors, had the most effects on the effectiveness of construction investment project management
\end{abstract} C 2020 by the authors: licensee Growing Science, Canada

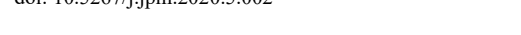


business environment, stabilizing the socio-economy, improving incomes, rising improve the quality of life of the people and creating local competitive advantages. There are many factors leading to construction investment projects being delayed, the level of construction investment projects has not been completed compared to the initial plan. From there, reducing the effectiveness when putting construction investment projects into operation or even making construction investment projects may fail. Therefore, it is important to identify the factors affecting the effectiveness of the construction investment project management from the beginning to the end of the construction investment project. Currently, Vietnam has not studied and evaluated the factors affecting the effectiveness of construction investment projects. Therefore, the main purpose of this study is to help the parties involved in construction investment projects to identify the causes affecting the progress of construction investment projects and management efficiency building projects. Therefore, the study of the factors affecting construction investment projects in small and medium enterprises in Vietnam is necessary and meaningful for the current period.

\section{Overview and research methodology}

\subsection{Literature Review}

The performance of project management was researched in a lot of papers in all over the world. Villafáñez et al. (2020) refered portfolio scheduling and project prioritization in Spain companies. Song et al. (2016) showed decentralized multi- project scheduling via multi- unit combinatorial auctions of China and Taiwan firms. Kiran and Reddy (2019) also showed the critical success factors of ERP implementation in SMEs of Bangladesh. Turner (1993) in the textbook project-based management referred the key factor influenced the success of the project management in SMEs. Villafanez et al. (2019) showed the multi-project scheduling problems with global resource constraints. Xuan et al. (2020) referred the factors affecting the business performance of enterprises in Vietnam. Especially, Vietnam SMEs faces the difficulties in construction project management both rural and urban areas. Xuan et al. (2020a) also referred the factors affecting the support services in small and medium sized enterprises in Vietnam. In addition, Xuan (2020a) noticed the importance of attracting the foreign direct investment in Vietnam project. Xuan (2020b) also referred the determinants of investment capital size in small and medium firm of Vietnam.

\subsection{Research Methodology}

The author uses qualitative research to identify the factors affecting the management of construction investment projects in small and medium enterprises in Vietnam. Survey data were collected from 458 small and medium-sized enterprises in Hanoi, Da Nang and Ho Chi Minh City. From there, the author proceeded to build the scale and consulted with experts in the field of construction, adjusted the scale, add observed variables in the group of influential factors to complete the survey questionnaire. Quantitative research aims to measure the influence of factors affecting construction investment projects and assess the reliability of the scale. At the same time, we test the research model. The study used a 5-level Likert scale (from 1: totally disagree to 5: totally agree) to quantify the scales. The author used SPSS 20.0 software to analyze data and some analytical methods were used in the topic such as descriptive statistical methods; Evaluate the reliability of Cronbach's Alpha reliability coefficient and Exploratory Factor Analysis (EFA) method. We also calculated the average value of the scale to assess the influence of independent factors on the dependent variable and multivariate regression analysis method was implemented to test the suitability of the research model. From that, the author proposed a research model including dependent variables and 06 independent variables. In particular, the dependent variable was the efficiency of construction investment projects; Independent variables were factors including (1) Consultants; (2) Investor; (3) Contractors; (4) Capital sources; (5) External factors and (6) Advantages in the implementation process of construction investment projects. Accordingly, the dependent variable (effective management of construction investment projects) and the independent variables were determined based on the research model as follows: 


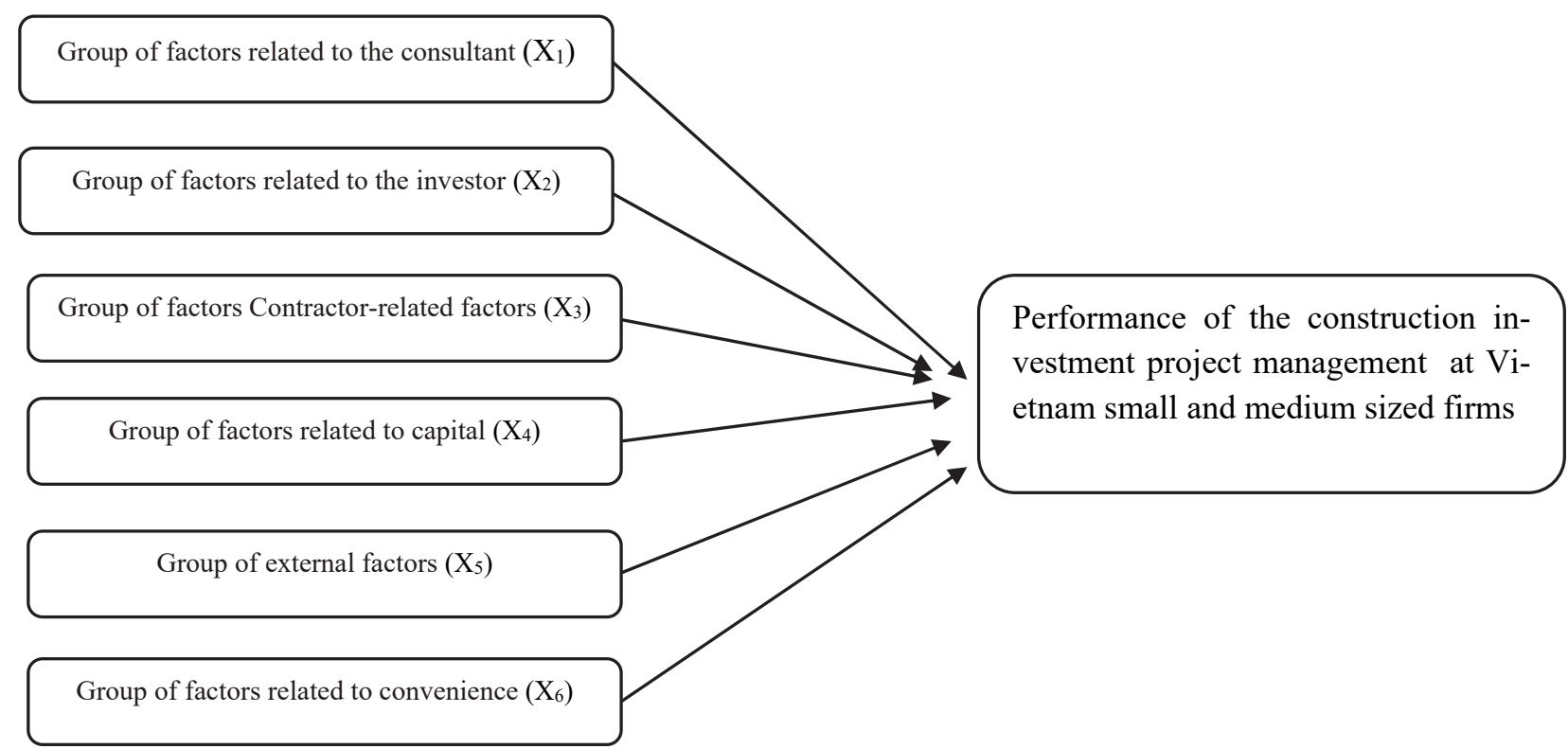

Fig. 1. The study process diagram of author

Xuan et al. (2020b), once again proved the favorable factors in project implementation and external factors affecting management effectiveness. Es's construction investment projects and the author also showed that the factors of capital, contractors, investors were factors that affect the efficiency of investment project management of enterprises. Therefore, in this study, the above factors were put into the analysis model by the author to determine the factors that affect the efficiency of construction investment project management of SMES. The research model is as follows:

$$
Y=\beta_{o}+\beta_{1} X_{1}+\beta_{2} X_{2}+\beta_{3} X_{3}+\beta_{4} X_{4}+\beta_{5} X_{5}+\beta_{6} X_{6}+\varepsilon
$$

where: The dependent variable $Y$ is effective management of construction investment projects. Variables $X_{1}, X_{2}, X_{3}, X_{4}, X_{5}$ and $X_{6}$ are independent variables (explanatory variables). From the nature of the independent variables, the model examined the influence of factors on investment project management of SMES in Vietnam and expected the sign of the variables in the model (See Table 1).

Specific Research and test the following hypotheses:

$\mathrm{H}_{1}$ : Consultants influence the effectiveness of construction investment project management of enterprises in Vietnam.

$\mathrm{H}_{2}$ : Investors influence the effectiveness of construction investment project management of enterprises.

$\mathrm{H}_{3}$ : Contractors influence the effectiveness of construction investment projects management by enterprises.

$\mathrm{H}_{4}$ : Factors related to capital affect the efficiency of construction investment project management of enterprises.

H5: Group of external factors affect the effectiveness of a company's construction investment project

H6: Group of factors related to convenience affect the effectiveness of the company's construction investment project management. 
Table 1

Interpretation of independent variables in the linear regression model

\begin{tabular}{llc}
\hline Variables & Explanation & Expectations \\
\hline X1 & Group of factors related to the consultant & + \\
X2 & Group of factors related to the investor & + \\
X3 & Group of factors Contractor-related factors & + \\
X4 & Group of factors related to capital & + \\
X5 & Group of external factors & + \\
X6 & Group of factors related to convenience & + \\
\hline
\end{tabular}

\section{Analysis results}

\subsection{Assessing the influence of independent factors on the effectiveness of construction investment project management in Vietnamese small and medium enterprises}

Table 2

Assessing the influence of the scale of factors in the model

\begin{tabular}{|c|c|c|c|c|c|}
\hline Observed variables & Symbol & No. & Mean & Std. Dev. & Level \\
\hline \multicolumn{6}{|c|}{ Group of factors related to consultant } \\
\hline Personal capacity of consultant Design & TV1 & 458 & 3.75 & 0952 & Influence much \\
\hline Capacity personal Consulting Supervision & TV2 & 458 & 3.88 & 0.866 & Influence much \\
\hline Personal capacity of Project Management Consulting & TV3 & 458 & 3.88 & 0.861 & High influence \\
\hline Capacity between Consultant and Investor & TV4 & 458 & 3.83 & 0.965 & Multiple influence \\
\hline Coordination capacity between the Consultant and the Contractor & TV5 & 458 & 3.87 & 0.972 & High Influence \\
\hline Capacity of the Consultant and Investor & TV6 & 458 & 4.15 & 0.928 & Multiple influence \\
\hline \multicolumn{6}{|c|}{ Group of factors related to Investor } \\
\hline Competence to subordinates & DT1 & 458 & 3.40 & 0.932 & High influence \\
\hline Negotiating power & DT2 & 458 & 3.55 & 0.983 & High impact \\
\hline Coordination capacity with Participants in construction investment projects & DT3 & 458 & 3.58 & 0.981 & Impact greatly \\
\hline Capacity to make decisions & DT4 & 458 & 3.60 & 0.979 & Impact much \\
\hline Capacity to solve difficulties and problems arising of construction investment projects & DT5 & 458 & 4.27 & 0711 & Impact lot of \\
\hline Awareness about the role and responsibilities of the investor & DT6 & 458 & 3.60 & 0915 & Influence multiple \\
\hline \multicolumn{6}{|l|}{$\begin{array}{ll}\text { Group factors related to contractor } \\
\end{array}$} \\
\hline Capacity of personnel of the main contractor & NT1 & 458 & 3.97 & 0815 & Influence much \\
\hline Financial capacity Contractor's Contractor & NT2 & 458 & 4.07 & 0.774 & High Influence \\
\hline Capacity of machines and equipment of $\mathrm{Nh}$ à main contractor & NT3 & 458 & 4.12 & 0.760 & Much influence \\
\hline Financial management capacity of the main contractor & NT4 & 458 & 4.14 & 0.761 & High impact \\
\hline Coordination capacity between the main contractor and the owner & NT5 & 458 & 4.10 & 0.769 & High influence \\
\hline Exchange capacity information between the Contractor and the Consultant and Investor & NT6 & 458 & 4.12 & 0.751 & Multiple impacts \\
\hline \multicolumn{6}{|l|}{ Group of factors related to Capital The } \\
\hline $\begin{array}{l}\text { Source of construction investment capital is sufficient and timely provided to the partici- } \\
\text { pating parties }\end{array}$ & NV1 & 458 & 3.78 & 0.830 & High influence \\
\hline Effective management of state financial resources & NV2 & 458 & 3.79 & 0.868 & High effect \\
\hline Balancing and allocating funds in line with the approved plan & NV3 & 458 & 3.91 & 0.753 & High influence \\
\hline Resolving correct capital payment documents regulations and timely & NV4 & 458 & 3.30 & 0.873 & Influence many \\
\hline \multicolumn{6}{|l|}{$\begin{array}{ll}\text { factors related to Foreigners } \\
\end{array}$} \\
\hline Inflationary finance & BN1 & 458 & 3.85 & 0.784 & High influence \\
\hline The increase in material prices out of control & BN2 & 458 & 3.97 & 0.738 & High impact \\
\hline Weather and geological conditions & $\mathrm{BN} 3$ & 458 & 3.98 & 0.702 & High impact \\
\hline Errors and inconsistencies in construction contracts & $\mathrm{BN} 4$ & 458 & 3.70 & 0.820 & High influence \\
\hline Regulatory agencies slow decision making & BN5 & 458 & 3.57 & 0.781 & High impact \\
\hline Complex legal procedures & BN6 & 458 & 3.39 & 0.790 & Multiple effects \\
\hline \multicolumn{6}{|c|}{ Factors related to Convenience } \\
\hline Full funding throughout the construction investment project & TL1 & 458 & 4.08 & 0.788 & High impact \\
\hline Comprehensive and comprehensive contract & TL2 & 458 & 4.14 & 0.804 & High impact \\
\hline Availability of resources & TL3 & 458 & 4.07 & 0.798 & High impact \\
\hline Participation Continuity of parties of construction investment projects & TL4 & 458 & 4.11 & 0.710 & Impact Article \\
\hline Payment procedures are clear instructions, quick, timely & TL5 & 458 & $4: 05$ & 0765 & Influence much \\
\hline sense of responsibility of the parties involved in the project construction investment & TL6 & 458 & 4:03 & 0988 & Influence much \\
\hline
\end{tabular}

Table 2 shows that all observed variables of the factors are assessed largely affect the management of construction investment projects in enterprises. 


\subsection{Cronbach's Alpha coefficients of analysis}

Table 3

Cronbach's Alpha test results of scales

\begin{tabular}{|c|c|c|c|c|}
\hline Variables Observation variables & Average scale & Variance Scale variance & Variable - Total & Cronbach's Alpha \\
\hline \multicolumn{5}{|c|}{ Consultant's scale: Cronbach's Alpha $=0.914$} \\
\hline TV1 & 15.46 & 9.589 & 0.790 & 0.893 \\
\hline TV2 & 15.33 & 10.174 & 0.765 & 0.899 \\
\hline TV3 & 15.33 & 9.860 & 0.805 & 0.891 \\
\hline TV4 & 15.38 & 9.671 & 0.893 & 0.793 \\
\hline TV5 & 15.34 & 9.574 & 0.900 & 0.759 \\
\hline \multicolumn{5}{|c|}{ Scale factor Owner: Cronbach's alpha $=\mathbf{0 . 9 1 3}$} \\
\hline DT1 & 10.72 & 7.043 & 0.808 & 0.885 \\
\hline DT2 & 10.58 & 7.394 & 0.780 & 0.894 \\
\hline DT3 & 10.55 & 7.282 & 0.809 & 0.884 \\
\hline DT4 & 10.52 & 7.294 & 0.809 & 0.884 \\
\hline \multicolumn{5}{|c|}{ Contractor factor scale: Cronbach's Alpha $=\mathbf{0 . 7 1 0}$} \\
\hline NT1 & 20.55 & 6,784 & 0.306 & 0.714 \\
\hline NT2 & 20.45 & 6.125 & 0.529 & 0.642 \\
\hline NT3 & 20.40 & 6.221 & 0.514 & 0.648 \\
\hline NT4 & 20.38 & 6.151 & 0.535 & 0.641 \\
\hline NT5 & 20.41 & 6.445 & 0.438 & 0.671 \\
\hline NT6 & 20.40 & 6.844 & 0.341 & 0.700 \\
\hline \multicolumn{5}{|c|}{ Scale factor Fund: Cronbach's alpha $=0.747$} \\
\hline NV1 & 7.70 & 1.991 & 0.565 & 0.674 \\
\hline NV2 & 7.70 & 1.897 & 0.566 & 0.676 \\
\hline NV3 & 7.57 & 2.122 & 0.599 & 0.642 \\
\hline \multicolumn{5}{|c|}{ Scale factor Peripherals: Cronbach's alpha $=\mathbf{0 . 8 0 3}$} \\
\hline BN1 & 15.21 & 5.538 & 0.557 & 0.775 \\
\hline $\mathrm{BN} 2$ & 15.10 & 5.742 & 0.543 & 0.779 \\
\hline $\mathrm{BN} 3$ & 15.09 & 5.700 & 0.601 & 0.762 \\
\hline BN4 & 15.37 & 5.201 & 0.624 & 0.754 \\
\hline BN5 & 15.50 & 5.371 & 0.615 & 0.756 \\
\hline \multicolumn{5}{|c|}{ Scale factor The advantage: Cronbach's alpha $=\mathbf{0 . 7 1 0}$} \\
\hline TL2 & 12.23 & 3.031 & 0.500 & 0.646 \\
\hline TL3 & 12.30 & 2.844 & 0.593 & 0.585 \\
\hline TL4 & 12.26 & 3.264 & 0.511 & 0.641 \\
\hline TL5 & 12.32 & 3.386 & 0.392 & 0.709 \\
\hline
\end{tabular}

The results presented in Table 3 show that, we need to remove some variables; namely TV6 variable (Supporting capacity of Consultants and Investors); DT5 (Capacity to solve difficulties and problems arising from construction investment projects); DT6 (Awareness of the roles and responsibilities of the Investor); Processing capital payment records in accordance with regulations and in time (NV4); Complicated legal procedures (BN6); Full funding throughout the construction investment project (TL1); and Awareness of responsibilities of construction investment project participants (TL6) since these observed variables correlate with unsatisfactory total variables $>0.3$. The results after eliminating all these variables are Cronbach's Alpha reliability $\geq 0.6$ and the correlation of variables - the sum of all variables - the total in the scales $>0.3$. Thus, the measurement variables of this factor are all used for subsequent factor discovery (EFA) analysis.

\subsection{Explore factor analysis results - EFA}

Table 4 shows that after separating the factor group, we find that the factor group (1) was related to the Consultant (TV3, TV4, TV5, TV1, TV2); factor groups (2) was related to the Investor (DT3, DT1, DT2, DT4); group of factors (3) was associated with peripheral factors (BN1, BN5, BN4, BN2, BN3); group of factors (4) is connected with the convenience of implementing construction investment projects (TL3, TL4, TL2, TL5); group of factors (5) were also related to the capital sources for execution of construction investment projects (NV1, NV2, NV3); finally, there was a factor group (6) related to the Contractor (NT2, NT3, NT1, NT4). Therefore, these groups of factors are suitable for analyzing the next regression model. 
Table 4

Factor rotation matrix

\begin{tabular}{|c|c|c|c|c|c|c|c|}
\hline & \multicolumn{7}{|c|}{ Component } \\
\hline & 1 & 2 & 3 & 4 & 5 & 6 & 7 \\
\hline TV3 & 0.863 & & & & & & \\
\hline TV4 & 0,837 & & & & & & \\
\hline TV5 & 0.823 & & & & & & \\
\hline TV1 & 0,810 & & & & & & \\
\hline TV2 & 0,800 & & & & & & \\
\hline DT3 & & 0.856 & & & & & \\
\hline DT1 & & 0.816 & & & & & \\
\hline DT2 & & 0.811 & & & & & \\
\hline DT4 & & 0.808 & & & & & \\
\hline BN1 & & & 0.772 & & & & \\
\hline BN5 & & & 0.739 & & & & \\
\hline $\mathrm{BN} 4$ & & & 0.718 & & & & \\
\hline $\mathrm{BN} 2$ & & & 0.690 & & & & \\
\hline $\mathrm{BN} 3$ & & & 0.6651 & & & & \\
\hline TL3 & & & & 0.778 & & & \\
\hline TL4 & & & & 0.725 & & & \\
\hline TL2 & & & & 0.725 & & & \\
\hline TL5 & & & & 0.664 & & & \\
\hline NV1 & & & & & 0.776 & & \\
\hline NV2 & & & & & 0.747 & & \\
\hline NV3 & & & & & 0.669 & & \\
\hline NT2 & & & & & & 0.788 & \\
\hline NT3 & & & & & & 0.673 & \\
\hline NT1 & & & & & & 0.666 & \\
\hline NT4 & & & & & & 0.558 & \\
\hline
\end{tabular}

\subsection{Analysis results of multivariate regression models}

Table 4

Parameters in the regression equation

\begin{tabular}{|c|c|c|c|c|c|c|c|c|}
\hline & \multirow{2}{*}{ Model } & \multicolumn{2}{|c|}{$\begin{array}{l}\text { Regression coefficients } \\
\text { not standardized }\end{array}$} & \multirow{2}{*}{$\frac{\text { Regression coefficients }}{\text { Beta }}$} & \multirow{2}{*}{$\mathbf{t}$} & \multirow{2}{*}{ Sig. } & \multicolumn{2}{|c|}{ Statistics } \\
\hline & & B & $\begin{array}{l}\text { Collinear } \\
\text { Std. Error }\end{array}$ & & & & Acceptance & VIF \\
\hline \multirow{7}{*}{1} & (Constant) & 0.860 & 0.460 & & 1.867 & 0.063 & & \\
\hline & $\mathrm{X} 1$ & 0.037 & 0,035 & 0.035 & 1.999 & 0.039 & 0.956 & 1.046 \\
\hline & $\mathrm{X} 2$ & 0.092 & 0,053 & 0.090 & 1.696 & 0.091 & 0.955 & 1.047 \\
\hline & $\mathrm{X} 5$ & 0.285 & 0,055 & 0.282 & 5.141 & 0.000 & 0.870 & 1.149 \\
\hline & X6 & 0.411 & 0,059 & 0.419 & 7.112 & 0.000 & 0.866 & 1.155 \\
\hline & X4 & 0.226 & 0,061 & 0.216 & 3.569 & 0.000 & 0.978 & 1.022 \\
\hline & $\mathrm{X} 3$ & 0.194 & 0067 & 0.184 & 2.724 & 0.007 & 0.961 & 1.040 \\
\hline
\end{tabular}

The results in Table 4 show, the value of sig. F of the model is $0.000<0.05$. Thus, the multivariate regression model was built in accordance with the specific overall:

- $\mathrm{R}^{2}$ reflects the degree of influence of the independent variables on the dependent variable. Specifically, in this case, 6 independent variables influence $74.1 \%$ of the variation of the dependent variable, the remaining $35.9 \%$ are due to non-model variables and random errors.

- Durbin - Watson is used to test the autocorrelation of adjacent errors (also known as first order correlation) whose values vary from 0 to 4 ; if the error is not correlated with the first order, the value will be close to 2; if the value is smaller, close to 0 , the errors are positively correlated; if larger, closer to 4 means that the errors are negatively correlated. The result of table 4 shows that Durbin Watson $=1.971$. Thus, it can be concluded that there was no superlative series correlation in the model. 
The results of Table 4 with Enter command shows that 6 independent variables of the model were the factors Consultant $\left(\mathrm{X}_{1}\right)$ and Investor $\left(\mathrm{X}_{2}\right)$, Peripheral $\left(\mathrm{X}_{5}\right)$, Advantages $\left(\mathrm{X}_{6}\right)$ ), Capital $\left(\mathrm{X}_{4}\right)$; The capacity of the main contractor (X3) is valuable Sig. very small (Sig. $<0.05)$. Therefore, all 6 partial regression coefficients are significant in the multivariate regression model.

In addition, the results in Table 4 show that the maximum value of the differential magnification factor (VIF) is $1.155<2$. Therefore, it is allowed to conclude that there is no multicollinearity phenomenon between the independent variables in Regression model is built.

Therefore, based on the summary results of the regression model in Table 4 allows to conclude as follows:

Firstly, the standardized regression model of the factors affecting the management of construction investment projects in the Vietnamese enterprises are determined as follows:

$$
Y=0.860+0.035 \times X_{1}+0.090 \times X_{2}+0.184 \times X_{3}+0.216 \times X_{4}+0.282 \times X_{5}+0.419 \times X_{6}
$$

Second, hypothesis $\mathrm{H}_{1}$ (The higher the capacity of the Consultant, the better the effectiveness of construction investment project management); and hypothesis $\mathrm{H}_{2}$ (The higher the capacity of the Investor, the better the management of construction investment projects) are accepted; The hypotheses: $\mathrm{H}_{3}, \mathrm{H}_{4}$, $\mathrm{H}_{5}, \mathrm{H}_{6}$ are also accepted and have been expressed through standardized regression equations.

Thirdly, the degree of influence of factors (in the condition of other factors being constant) to the management of construction investment projects in Vietnam is determined as follows:

- Factors related to Advantages in the process of executing construction investment projects are the factors that have the strongest influence on the effectiveness of the construction investment project management in Vietnam. Specifically, if the favorableness is assessed to increase by $1 \%$, the effectiveness of construction project management will increase by $0.419 \%$.

- Peripheral factors in the process of executing construction investment projects are the second most influential factors in the management of construction investment projects in small and medium-sized enterprises in Vietnam. Specifically, the stability level of Peripheral factors is assessed to increase by $1 \%$, the effectiveness of construction investment project management will increase by $0.282 \%$.

- Capital-related factors in the process of executing construction investment projects are the third most influential factors in managing construction investment projects in small and medium-sized enterprises in Vietnam. Specifically, if the capital source during the execution of a construction investment project is assessed to increase by $1 \%$, the efficiency of construction investment project management will increase by $0.216 \%$.

- Factors related to contractor capacity are the most influential factors to the effectiveness of the construction investment project management. Specifically, the main contractor capacity in the process of implementing a construction investment project is estimated to increase by $1 \%$, the efficiency of construction investment project management will increase by $0.184 \%$.

\section{Recommendations to the parties involved in construction investment projects in Vietnam}

-For the factor Advantages in the process of implementing construction investment projects:

Research results show that, Advantages in The implementation of construction investment projects is the most important factor affecting the effectiveness of construction investment projects management in small and medium-sized enterprises in Vietnam $($ Beta $=0.419)$. However, in order to consolidate 
and increase the efficiency of construction investment projects, the Government of Vietnam and local governments, state administrative agencies need to focus on solving urgent issues such as quick implementation. promptly and timely guide the payment procedures in each stage of construction investment projects; focus on improving the reform of administrative procedures to avoid troubles in transactions when making payment; need to ensure the adequacy of capital in construction; When bidding, the contract is an important legal document that binds and binds the responsibility between the contractor and the investor, both in terms of contract performance and payment responsibility; There should be strict regulations in the selection of the Investor, the Contractor or the Consultant who must specify specific conditions to raise the sense of responsibility of the parties involved in the construction investment project.

\section{-For Peripheral factors in the process of implementing a construction investment project:}

Peripheral factors are the second most important factor (after the Convenience factor) affecting project management efficiency construction investment projects in small and medium enterprises in Vietnam (Beta $=0.282)$. In this factor, the issue of weather, natural conditions, price, inflation, is almost an external objective factor affecting the effectiveness of the construction investment project management, the participants only can partially overcome this problem during construction. Therefore, in order to consolidate and speed up the completion of construction investment projects, the central and local governments of Vietnam provinces and state administrative agencies should pay attention and settle on the time factors. Partly, if it is not overcome well, it may cause construction problems, this is a problem that the parties involved in construction investment projects need to pay special attention to; In contrast to the weather that will affect construction investment projects during construction, geological issues will affect the progress of construction investment projects at the design stage; Financial inflation and raw material prices rise beyond control, this issue requires the intervention of the state apparatus, more effective macro-control policies or specific policies to support the sector. construction area.

-For Capital sources in the process of executing construction investment projects:

Capital factors are the third most important factor affecting the efficiency of construction investment project management in enterprises. Vietnamese small and medium enterprises (Beta $=0.216)$. The parties involved in the construction investment project assess the factors of capital resources in the process of implementing the construction investment project at the present time which is important but most of the funding source is not sufficient and timely for the parties to construction investment projects. This is entirely grounded, because the fact that when disbursing capital to contractors, consultants or parties to construction investment projects is largely behind schedule. The reason is that the procedure must be signed through many stages and parts. Therefore, the locality has policies to adjust the capital allocation mechanism of construction investment such as putting the number of completed works and the implementation schedule into evaluation criteria to allocate the annual construction capital plan; It is necessary to concentrate capital sources on construction investment projects with high efficiency, giving priority to construction investment projects with high efficiency, with priority given to quickly and prioritized construction investment projects. giving priority to construction investment projects to effectively manage the allocated capital, limit the widespread capital allocation, spread investment, and ineffective financial management.

-For the main contractor capacity factor in the process of construction investment project implementation: factors

The contractor capacity is the factor that affects the efficiency of construction investment project management. built in Vietnam $($ Beta $=0.184)$. The parties involved in the construction investment project evaluate and pay attention to the main competence of the contractor This is entirely reasonable, because it is a factor that can be controlled from the beginning when the investment project has 
not been implemented. build. Right from the initial work, when selecting contractors, it is necessary to have a close evaluation in selecting contractors, especially in the bidding process, to avoid the situation of choosing contractors to bid cheaply but with competitive competence. There are still many shortcomings, causing many projects to be delayed, not up to quality. So seriously, openly bidding work; limiting the low bid price, prioritizing the selection of contractors based on technical capacity, experience, and financial capacity will help the Investor to have more options to select the preferred contractor than the only interested in bidding value; Capacity factors need to be kept throughout the implementation process of construction investment projects, that is, must be strictly implemented under the signed contract; supervision of contract performance should be attached to sanctions and sanctions when breaching contracts. That is one of the reasons to consolidate and speed up the completion of construction investment projects in small and medium enterprises in Vietnam.

\section{Conclusion}

The study has built 6 groups of factors affecting the effectiveness of construction investment projects management in small and medium-sized enterprises in Vietnam including: (1) Consultants; (2) Investors; (3) Contractors; (4) Capital sources; (5) Peripheral; and (6) Convenience.

With 6 components and a scale of factors affecting the effectiveness of construction investment projects management in small and medium-sized enterprises in Vietnam, they all achieve the permitted reliability.

The results of the research on factors affecting the effectiveness of construction investment project management in Vietnamese enterprises show that the research objectives have been achieved. However, like many other studies, this study still has some research limitations that can only be tested for construction investment projects in big cities such as Hanoi, Da Nang and Ho Chi Minh. Research samples were selected by convenient sampling methods, so the generalization of the research results is not high.

\section{References}

Kiran, T., \& Reddy, A. (2019). Critical success factors of ERP implementation in SMEs. Journal of Project Management, 4(4), 267-280.

Song, W., Kang, D., Zhang, J., \& Xi, H. (2016, May). Decentralized multi-project scheduling via multi-unit combinatorial auction. In Proceedings of the 2016 International Conference on Autonomous Agents \& Multiagent Systems (pp. 836-844).

Toffolo, T. A., Santos, H. G., Carvalho, M. A., \& Soares, J. A. (2016). An integer programming approach to the multimode resource-constrained multiproject scheduling problem. Journal of Scheduling, 19(3), 295-307.

Turner, J. R. (1993). The handbook of project-based. Management, McGraw-Hill, Boston..

Villafáñez, F. A., Poza, D., López-Paredes, A., \& Pajares, J. (2018). A unified nomenclature for project scheduling problems (RCPSP and RCMPSP). Dirección y Organización, 64, 56-60.

Villafáñez, F., \& Poza, D. J. (2010). Propuesta de Modelo MAS para la resolución del RCMPSP basado en Subastas Combinatorias. Best practices in project management. Methodologies and case studies in construction and engineering. INSISOC, Valladolid, Spain.

Villafáñez, F., Poza, D., López-Paredes, A., Pajares, J., \& del Olmo, R. (2019). A generic heuristic for multi-project scheduling problems with global and local resource constraints (RCMPSP). Soft Computing, 23(10), 3465-3479.

Villafáñez, F., Poza, D., López-Paredes, A., Pajares, J., \& Acebes, F. (2020). Portfolio scheduling: an integrative approach of limited resources and project prioritization. Journal of Project Management, 5(2), 103-116. 
Xuan, V., Thu, N., \& Anh, N. (2020a). Factors affecting the business performance of enterprises: Evidence at Vietnam small and medium-sized enterprises. Management Science Letters, 10(4), 865-870.

Xuan, V., Thu, N., \& Anh, N. (2020b). Factors affecting support services in small and medium enterprises: Evidence from Vietnam small and medium information technology enterprises. Management Science Letters, 10(2), 303-312.

Xuan, V. N. (2020a). Factors affecting foreign direct investment: Evidence at foreign technology enterprises in Vietnam. International Journal of Advanced and Applied Science, 7(4), 21-28.

Xuan, V.N. (2020b). Determinants of Investment Capital Size: A Case of Small and Medium-Sized Enterprises in Vietnam. Journal of Asian Finance, Economics and Business, 7(6), 115-125.

Zheng, Z., Guo, Z., Zhu, Y., \& Zhang, X. (2014). A critical chains based distributed multi-project scheduling approach. Neurocomputing, 143, 282-293.

Zuluaga, A., Sefair, J. A., \& Medaglia, A. L. (2007, April). Model for the selection and scheduling of interdependent projects. In 2007 IEEE Systems and Information Engineering Design Symposium (pp. 1-7). IEEE.

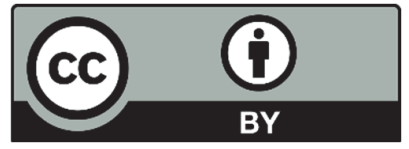

(C) 2020 by the authors; licensee Growing Science, Canada. This is an open access article distributed under the terms and conditions of the Creative Commons Attribution (CC-BY) license (http://creativecommons.org/licenses/by/4.0/). 